\title{
Artikel
}

\section{Tenuitvoerlegging van een grosse van een notariële akte in het erfrecht}

\author{
Prof. dr. S. Perrick*
}

\section{Inleiding}

Het is advocaten en notarissen bekend dat niet alleen grossen van vonnissen en beschikkingen, maar ook grossen van in Nederland verleden authentieke akten in Nederland ten uitvoer kunnen worden gelegd. Dat volgt uit artikel 430 e.v. van het Wetboek van Burgerlijke Rechtsvordering $(\mathrm{Rv}){ }^{1}$ Ook in het erfrecht zijn er mogelijkheden om een grosse van een notariële akte ten uitvoer te leggen. In dit artikel besteed ik aandacht aan een aantal gevallen waarin dit in de praktijk van belang kan zijn. Ik sta allereerst kort stil bij het geval dat erflater partij was bij een notariële akte. Daarbij maak ik een onderscheid tussen het geval dat het gaat om de tenuitvoerlegging van een vordering op de erflater, dat wil na diens overlijden zeggen: een vordering die correspondeert met een schuld van de nalatenschap als genoemd in artikel 4:7 lid 1 onder a of $\mathrm{i} \mathrm{BW}{ }^{2}$ en het geval dat het gaat om een vordering van de erflater, dat wil na diens overlijden zeggen: een vordering van de nalatenschap.

Prof. dr. S. Perrick is advocaat te Amsterdam.

1. In het geval van een executoriale verkoop door de pand- of hypotheekhouder op de voet van art. 3:248 onderscheidenlijk art. 3:268 BW heeft de pand- of hypotheekhouder geen grosse van de (notariële) pandakte of de hypotheekakte nodig. De pand- of hypotheekhouder is ook zonder dat hij over een executoriale titel beschikt bevoegd tot parate executie. Zie Asser/Van Mierlo 3-VI 2016/156 en 394.

2. Bij een schuld als bedoeld in art. 4:7 lid 1 onder i BW is in het bijzonder te denken aan een gift ter zake des doods, die op grond van art. 4:126 lid 1 BW een fictief legaat is. Deze gift vervalt ingevolge art. 7:177 lid 1 BW, al dan niet in verbinding met art. 7:186 BW, met het overlijden van de erflater indien zij niet reeds tijdens het leven door de erflater/schenker is uitgevoerd, tenzij de gift door de erflater persoonlijk is aangegaan en van de gift een notariële akte is opgemaakt.
Is een notaris bij de afwikkeling van een gemeenschap van nalatenschap betrokken, dan zal in het algemeen de verdeling van de gemeenschap wel bij notariële akte plaatsvinden. En in geval van een wettelijke verdeling zal de akte houdende vaststelling van de geldvorderingen van de kinderen wel in een notariële akte worden neergelegd indien er een notaris is betrokken bij deze vaststelling. ${ }^{3}$

Wordt bij een verdeling van een gemeenschap van nalatenschap aan een erfgenaam, meestal een kind van erflater, een vordering toebedeeld wegens overbedeling van een erfgenaam, meestal de langstlevende, dan dient dit kind, of zijn advocaat, zich te realiseren dat een grosse van de notariële akte van verdeling ten uitvoer kan worden gelegd zodra de vordering uit hoofde van overbedeling opeisbaar is en de schuldenaar, de langstlevende of zijn erfgenamen, in verzuim is met betaling van de schuld. Hetzelfde geldt mutatis mutandis ten aanzien van een geldvordering uit hoofde van een wettelijke verdeling.

Ook voor een legataris van een geldlegaat is het van belang dat hij zich realiseert dat hij zodra er verzuim in de afgifte van het legaat is ingetreden, geen veroordeling van de erfgenaam/erfgenamen door een rechter nodig heeft om zich te kunnen verhalen op een goed van de nalatenschap en/of een overig goed van een erfgenaam op wie het legaat rust.
3. De Kamer voor het Notariaat Arnhem-Leeuwarden 25 juli 2019, Notamail 2019/168, oordeelde dat een notaris die voor het vastleggen van een rechtshandeling de keuze heeft tussen een onderhandse en een authentieke akte partijen dient te informeren over het verschil tussen beide mogelijkheden en de gevolgen van een keuze in het desbetreffende geval. Een relevant verschil kan zijn de mogelijkheid van tenuitvoerlegging van een grosse van een notariële akte. 
Ik herinner de lezer eraan dat de notaris geen grosse mag afgeven van een verklaring van erfrecht. Zie artikel 50 lid 3 van de Wet op het notarisambt (Wna). ${ }^{4}$

Volgens artikel 49 Wna mag de notaris, voor zover bij of krachtens de wet niet anders is bepaald, van de tot zijn protocol behorende notariële akten (onder meer) afschriften, uittreksels en grossen uitgeven aan partijen bij de akten, daaronder begrepen de rechtverkrijgenden onder algemene titel. Indien er een executeur of vereffenaar in functie is, dient uitgifte van het afschrift, het uittreksel of de grosse van een akte waarbij de erflater partij is, aan deze plaats te vinden.

Met een grosse van een vonnis kan reële executie van een verplichting tot betaling van een geldsom plaatsvinden.

Bij de zojuist gegeven voorbeelden ging het ook om verhaalsexecutie ter zake van een geldvordering. In artikel 3:299 e.v. van het Burgerlijk Wetboek (BW) wordt geregeld onder welke voorwaarden reële executie van een andere verplichting dan een verplichting tot betaling van een geldsom kan geschieden. Het gaat bij een andere verplichting om een verplichting tot een nalaten en om een verplichting om een (rechts)handeling te verrichten. Artikel 3:299 BW voorziet in de mogelijkheid dat de rechter degene jegens wie een verplichting tot een doen of nalaten bestaat op diens vordering machtigt om zelf datgene te bewerken waartoe nakoming zou hebben geleid. En artikel 3:300 BW ziet op het geval dat iemand jegens een ander is gehouden een rechtshandeling te verrichten. In dat geval kan de rechter op vordering van de gerechtigde bepalen dat zijn uitspraak dezelfde kracht heeft als een in wettige vorm opgemakte akte van degene die tot de rechtshandeling is gehouden, of dat een door hem aan te wijzen vertegenwoordiger de handeling zal verrichten.

Ook met een grosse van een notariële akte kan reële executie van een andere verplichting dan die tot betaling van een geldsom plaatsvinden. Naar mijn mening kan de schuldenaar van een verplichting om te doen de schuldeiser in een notariële akte machtigen om zonder tussenkomst van de rechter de verplichting na te komen. ${ }^{5}$ Eveneens acht ik het mogelijk dat de schuldeiser in een notariële akte door de schuldenaar wordt gemachtigd om als diens vertegenwoordiger een rechtshandeling te verrichten. Het is twijfelachtig of in de notariële akte met effect kan worden bepaald dat de notariële akte dezelfde kracht heeft als een in wettige vorm opgemaakte akte van degene die tot de rechtshandeling is gehouden. ${ }^{6,7}$

4. Deze constatering is in de context van dit artikel van belang indien een notariële akte van erfrecht vermeldt aan wie de erflater een bepaald (geld)legaat heeft vermaakt.

5. Aldus ook B.C.M. Waaijer, Melis. De Notariswet, Deventer: Wolters Kluwer 2019, nr. 11.2

6. Zie Melis/Waaijer, De Notariswet, nr. 11.2 en C.A. Kraan, De Bruijn. De notariële akte als executoriale titel, Deventer: Kluwer 2012, nr. 8.15.

7. Is de verdeling van een registergoed in een notariële akte vastgelegd, dan zal inschrijving van een afschrift van of een uittreksel uit de akte in de openbare registers slechts overgang van het registergoed kunnen bewerkstelligen indien er aanwijzingen zijn dat de notariële akte de voor
In dit artikel besteed ik verder uitsluitend aandacht aan de verhaalsexecutie van een verplichting tot betaling van een geldsom. Verhaalsexecutie is naar mijn mening eerst mogelijk nadat de schuldenaar in verzuim is de schuld te voldoen; het is niet voldoende dat de met de schuld corresponderende vordering opeisbaar is. ${ }^{8}$

\section{Notariële akte waarbij erflater partij was}

In het geval dat de erflater partij was bij een notariële akte, waarin bijvoorbeeld een overeenkomst van geldlening met de erflater als geldnemer is neergelegd, kan een grosse van deze akte op de goederen van de nalatenschap ten uitvoer worden gelegd.

Executoriaal beslag moet worden voorafgegaan door een exploot van een deurwaarder, houdende bevel om binnen twee dagen aan de executoriale titel te voldoen. Eerst na verloop van die termijn kan het beslag worden gelegd. Aldus artikel 439 lid 1 eerste en tweede zin Rv voor roerende zaken die geen registergoederen zijn en artikel 502 lid 1 eerste en tweede zin $\mathrm{Rv}$ voor onroerende zaken. Verlopen twee dagen na de betekening zonder dat betaling heeft plaatsgevonden, dan is de schuldenaar in verzuim.

De tenuitvoerlegging van de grosse kan plaatsvinden op goederen van de nalatenschap. Waar de wet betekening aan de geëxecuteerde voorschrijft, dient daarvoor te worden gelezen de enige erfgenaam of de gezamenlijke erfgenamen. ${ }^{9}$ Is er een executeur of vereffenaar in functie, dan dient betekening aan deze plaats te vinden. ${ }^{10}$

Verhaalsexecutie op goederen van de nalatenschap zal in beginsel niet kunnen plaatsvinden indien de nalatenschap overeenkomstig afdeling 4.6.3 BW wordt vereffend. Zie artikel 4:223 lid $1 \mathrm{BW}$, dat bepaalt dat een schuldeiser gedurende de vereffening alleen bevoegd is zijn vordering op goederen van de nalatenschap ten uitvoer te leggen indien deze bevoegdheid hem ook in geval van faillissement van de erflater zou zijn toegekomen. ${ }^{11}$

levering bestemde akte is. Zie daarover Asser/Perrick 3-V 2019/189. Aan de tenuitvoerlegging van een grosse van deze akte bestaat in dat geval geen behoefte. leder der partijen bij de akte van verdeling is bevoegd een afschrift van of een uittreksel uit de akte in de openbare registers te doen inschrijven.

8. Zie par. 2 over het belang van het bevel tot betaling in dit verband. Vgl. art. 3:248 en 3:268 BW op grond waarvan de pand- onderscheidenlijk hypotheekhouder eerst tot parate executie bevoegd is wanneer de schuldenaar in verzuim is.

9. Daarbij kan gebruik worden gemaakt van de faciliteit van art. 53 Rv.

10. Volgens art. 53 aanhef en onder b Rv kan vermelding van de namen en de woonplaatsen van de gezamenlijke erfgenamen achterwege blijven indien de betekening geschiedt 'aan de persoon of de woonplaats van een executeur of door de rechtbank benoemde vereffenaar van de nalatenschap, van een ten tijde van het overlijden fungerend curator of bewindvoerder (...)'.

11. Zie daarover Asser/Perrick 4 2017/643. Art. 33 Fw, op grond waarvan ten gevolge van het faillissement onder meer alle gelegde beslagen vervallen, is niet van overeenkomstige toepassing verklaard in geval van 
Bijzondere aandacht verdient het geval dat de erflater over de nalatenschap of over één of meer erfdelen een testamentair bewind heeft ingesteld. Ik beperk mij hier tot het geval dat het bewind in het belang van de individuele erfgenaam/erfgenamen is ingesteld. ${ }^{12}$ Volgens artikel 4:175 lid 1 aanhef en onder a BW kunnen tijdens het bewind de onder bewind staande goederen ten laste van de rechthebbende, lees: de erfgenaam, onder meer worden uitgewonnen voor de schulden van de nalatenschap.

Indien een erfgenaam zuiver heeft aanvaard, kan de tenuitvoerlegging van de grosse ook plaatsvinden ten laste van het 'overig vermogen' ${ }^{13}$ van een erfgenaam. ${ }^{14}$ Vereffening van de nalatenschap staat daaraan niet in de weg. ${ }^{15}$

Gaat het om een notariële akte waaruit een vordering van erflater tot betaling van een geldsom voortvloeit, bijvoorbeeld een notariële akte waarin een overeenkomst van geldlening met de erflater als geldgever is neergelegd, dan is eveneens verhaalsexecutie met de grosse van de notariële akte mogelijk. Hierbij is wel van belang artikel 431a Rv, dat bepaalt dat indien de bevoegdheid tot tenuitvoerlegging van een executoriale titel op een ander overgaat, de executie eerst kan worden aangevangen of voortgezet na betekening van deze overgang aan de geëxecuteerde. Voor het onderwerp van dit artikel betekent dit het volgende. Indien de erflater reeds met de executie van de grosse was begonnen, dienen zijn erfgenamen de overgang van de bevoegdheid tot tenuitvoerlegging van een grosse van de notariële akte, die een gevolg is van de erfopvolging, eerst aan de schuldenaar te betekenen, alvorens zij de executie kunnen voortzetten. Was de erflater nog niet met de executie begonnen, dan kunnen zijn erfgenamen daartoe eerst overgaan na betekening van de overgang krachtens erfrecht. Komt het beheer van de goederen van de nalatenschap toe aan een executeur of een vereffenaar, dan is deze bevoegd de executie aan te vangen of voort te zetten. ${ }^{16} \mathrm{Na}$ de betekening van de overgang is de nalatenschap bevoegd tot tenuitvoerlegging van een grosse van deze akte. Voor 'nalatenschap' dient te worden gelezen: degene(n) aan wie het beheer over deze vordering toekomt. Dat wil zeggen de gezamenlijke erfgenamen ${ }^{17}$ of de enige erfge-

vereffening. Daaraan bestaat, in aanmerking genomen art. 4:223 lid 1 BW, geen behoefte. Zie Asser/Perrick 4 2017/602a.

12. Ik ga er in het navolgende van uit dat er niet tevens een executeur in functie is en dat de nalatenschap ook niet wordt vereffend overeenkomstig de wet. Is er een executeur of vereffenaar in functie, dan is deze niettegenstaande het bewind bevoegd de schulden van de nalatenschap, waaronder een legaat, te voldoen. Zie uitgebreider: S. Perrick, Tenuitvoerlegging van een executoriale titel strekkende tot betaling van een schuld van de nalatenschap, WPNR 2012, afl. 6938, nr. 2.7.

13. Terminologie ontleend aan art. 4:184 lid 2 BW.

14. Aldus ook De Bruijn/Kraan, De notariële akte als executoriale titel, nr. 7.4

15. S. Perrick, Insolventie en erfrecht (preadvies KNB 2011), Den Haag: Sdu Uitgevers 2011, nr. 3.5.3.

16. Eventueel kan deze bevoegdheid aan een bewindvoerder toekomen, al dan niet tezamen met een erfgenaam.

17. Dezen kunnen op de voet van art. 3:168 lid 1 BW een beheersregeling zijn overeengekomen of de kantonrechter kan op grond van art. 3:168 lid 2 BW een beheersregeling hebben getroffen. naam of de executeur of vereffenaar en eventueel (mede) een bewindvoerder indien over één of meer erfdelen een bewind is ingesteld.

\section{Notariële akte van verdeling}

De verdeling van een gemeenschap van nalatenschap kan geschieden in de vorm die partijen goeddunkt. Zie artikel 3:183 lid $1 \mathrm{BW}$, dat ook bepaalt dat dit slechts geldt als de deelgenoten en zij wier medewerking is vereist het vrije beheer over hun goederen hebben en in persoon of bij een door hen aangewezen vertegenwoordiger meewerken, dan wel in geval van bewind worden vertegenwoordigd door de bewindvoerder voorzien van de daartoe vereiste toestemming of machtiging. In andere gevallen moet, tenzij de rechter anders bepaalt, de verdeling plaatsvinden bij notariële akte en worden goedgekeurd door de kantonrechter, die bevoegd is de wettelijke vertegenwoordiger van degene die het vrije beheer over zijn goederen mist tot beschikkingshandelingen te machtigen. ${ }^{18}$ De verdeling kan dus, tenzij uit artikel 3:183 BW anders voortvloeit, bij onderhandse akte of ook mondeling geschieden. De vraag die in dit artikel centraal staat, is of, en zo ja wanneer, executie van een grosse van een notariële akte van verdeling mogelijk is. In zoverre die vraag bevestigend wordt beantwoord, kan dat een (extra) argument zijn om de verdeling in een notariële akte neer te leggen, ook wanneer artikel 3:183 BW geen notariële akte voorschrijft. Ik begin met een eenvoudig voorbeeld. De verdeling van een gemeenschap van nalatenschap met twee erfgenamen geschiedt bij notariële akte. De verdeling geschiedt aldus dat alle goederen van de nalatenschap aan één deelgenoot, de langstlevende echtgenoot, worden toebedeeld, terwijl aan de andere deelgenoot, een kind van erflater, een vordering tot 'vergoeding van de overwaarde $^{19}$ wordt 'toebedeeld'. De term 'toebedeeld' is in zoverre onjuist dat de vordering wegens overbedeling niet een goed betreft dat tot de gemeenschap van de nalatenschap behoort. De verdeling heeft tot gevolg dat de overbedeelde deelgenoot schuldenaar is geworden van een schuld die correspondeert met de vordering van de onderbedeelde deelgenoot tot betaling van een geldsom ter grootte van de overbedeling. De deelgenoten kunnen overeenkomen dat de geldsom eerst na verloop van zekere tijd, hetzij ineens, hetzij in termijnen behoeft te worden voldaan. Ook de rechter kan dat op grond van artikel 4:5 BW bepalen. In de akte van verdeling kunnen de deelgenoten voor het geval de schuld uit hoofde van overbedeling niet ineens behoeft te worden voldaan ook afspraken over de verschuldigde (contractuele) rente neerleggen. Van een aanspraak op mettelijke rente over een te vergoeden overwaarde kan eerst sprake zijn wanneer het tot verdeling is gekomen en de overbedeelde

18. Zie laatstelijk over art. 3:183 BW: S. Perrick, Tijdschrift Erfrecht 2019, afl. 3, p. 50-51.

19. Terminologie ontleend aan art. 3:185 lid 2 onder b BW. 
deelgenoot in verzuim is. ${ }^{20}$ Wordt aan de overbedeelde deelgenoot een termijn gegund om de schuld wegens overbedeling te voldoen, dan verdient het aanbeveling in de akte van verdeling te bepalen dat de deelgenootschuldenaar na het verstrijken van de termijn overeenkomstig artikel 6:119 BW de wettelijke rente is verschuldigd. ${ }^{21}$ Er bestaat naar mijn mening geen twijfel over dat de grosse van een notariële akte van verdeling in de terminologie van artikel $430 \mathrm{Rv}$ kan 'worden ten uitvoer gelegd' voor zover het de vordering op de overbedeelde deelgenoot betreft. Dat betekent dat de schuldeiser van de vordering wegens overbedeling executoriaal beslag kan leggen op vermogensbestanddelen van de overbedeelde ex-deelgenoot/schuldenaar. Uit artikel 480 e.v. Rv en artikel 551 e.v. Rv, voor onroerende zaken, volgt hoe de verdeling van de opbrengst van de executoriaal verkochte goederen plaatsvindt. In het meest eenvoudige geval, dat is indien er geen andere schuldeiser is, die op het executoriaal beslagen goed of de opbrengst van de executie ${ }^{22}$ beslag heeft gelegd, en evenmin een beperkt gerechtigde bekend is wiens recht door de executie is vervallen, keert de deurwaarder de netto-opbrengst aan de executant tot het beloop van diens vordering uit. Het beloop van de vordering van de executant wordt mede bepaald door over de vordering wegens overbedeling verschuldigde rente. Een eventueel overschot wordt aan de geëxecuteerde afgedragen.

Hiervoor ben ik ervan uitgegaan dat tenuitvoerlegging van een grosse van de notariële akte plaatsvindt. Volgens artikel 1 lid 1 aanhef en onder f Wna wordt in deze wet verstaan onder grosse een in executoriale vorm uitgegeven afschrift of uittreksel van een notariële akte. Dus ook een grosse van een uittreksel van een notariële akte kan worden geëxecuteerd. Dit is in het bijzonder van belang in het geval dat de executant slechts recht heeft op afgifte door de notaris van een uittreksel van de notariële akte. Zie paragraaf 5 hierna.

\section{Notariële akte houdende vaststelling van geldvordering in geval van wettelijke verdeling}

Is er sprake van een wettelijke verdeling, dan geschiedt de vaststelling van de geldvorderingen van de kinderen in beginsel door de langstslevende en de kinderen gezamenlijk. De wet besteedt geen aandacht aan de wijze waarop en de vorm waarin de vaststelling van de geldvorderingen dienen plaats te vinden in het geval de erfgenamen niet allen het vrije beheer over hun goederen hebben en niet allen bij een door hen aangewezen verte-

20. Zie Asser/Perrick 3-V 2019/173 en de daar vermelde rechtspraak.

21. Zie Asser/Perrick 3-V 2019/173 en de daar vermelde rechtspraak.

22. Bij de executoriale verkoop van een onroerende zaak dient voor 'opbrengst van de zaak' te worden gelezen 'koopprijs', zie art. 551 lid 3 Rv. genwoordiger aan de vaststelling meewerken. ${ }^{23}$ Worden de geldvorderingen bij notariële akte vastgesteld, dan kan een kind tot executie van een grosse overgaan op het tijdstip dat de geldvordering opeisbaar is geworden en de langstlevende, of zijn erfgenamen, in verzuim is.

Geschiedt de vaststelling van de geldvorderingen door de kantonrechter op de voet van artikel 4:15 lid 1 BW, dan is de vraag of executie kan plaatsvinden van een grosse van de beschikking van de kantonrechter. Het lijkt voor de hand te liggen die vraag bevestigend te beantwoorden. Volgens artikel 430 lid $1 \mathrm{Rv}$ kunnen immers grossen van beschikkingen van de Nederlandse rechter ten uitvoer worden gelegd.

\section{Notariële uiterste wil houdende de making van een geldlegaat}

Heeft een erflater in een notariële uiterste wil een legaat gemaakt, dan heeft de legataris op grond van artikel 49 lid 1 aanhef en onder $b$ in verbinding met artikel 50 lid 2 onder c Wna recht op een grosse van een uittreksel van de uiterste wil van dat gedeelte van de akte dat rechtstreeks van belang is voor zijn recht, dat wil zeggen het aan hem gemaakte legaat. Indien het legaat opeisbaar is en de erfgenamen zijn in verzuim, kan de legataris overgaan tot executie van de grosse van het uittreksel van de uiterste wilsbeschikking dat het legaat en de voorwaarden waaronder dat is gemaakt, bevat. ${ }^{24}$

Voor de tenuitvoerlegging op goederen van de nalatenschap verwijs ik naar paragraaf 2 . Omdat het legaat een schuld van de nalatenschap is, kan volgens artikel 4:175 lid 1 aanhef en onder a BW tijdens het bewind een onder bewind staand goed daarvoor worden uitgewonnen.

Bij een legaat dat niet op alle erfgenamen rust, is voorts verhaal mogelijk op goederen van een erfgenaam op wie het legaat rust en die de nalatenschap zuiver heeft aanvaard. Bij een geldlegaat, dat een deelbare verbintenis is, en dat op meer dan één erfgenaam rust, is tenuitvoerlegging van de grosse van de uiterste wil slechts mogelijk op het overig vermogen van iedere erfgenaam op wie het legaat rust voor het aandeel dat deze betreft.

Is er niet sprake van een bevoordeling door middel van een legaat, maar van een lastbevoordeling, dan is verhaalsexecutie op grond van een grosse van een uittreksel van de uiterste wil niet mogelijk, ook niet indien de last

23. Zie Asser/Perrick 4 2017/87

24. Aldus Rb. Zeeland-West-Brabant (vzr.) 25 juli 2018, ECLI:NL:RBZWB: 2018:5938. In deze zaak had de notaris zich onder verwijzing naar HR 26 juni 1992, ECLI:NL:HR:1992:ZC0646, NJ 1993/449 en HR 8 februari 2013, ECLI:NL:HR:2013:BY4889, NJ 2013/123 op het standpunt gesteld dat er voor hem een gegronde reden is om afgifte van de grosse te weigeren. De kantonrechter oordeelt terecht dat de vordering van de legataris voldoende bepaalbaar is en dat het in het testament opgenomen legaat een vordering is onder opschortende voorwaarde. 
tot een uitgave van geld of van een goed van de nalatenschap verplicht. Beslissend is dat aan de lastbevoordeelde geen vorderingsrecht toekomt. ${ }^{25}$

\section{Overgang conservatoir beslag in executoriaal beslag}

Een schuldeiser kan eerst executoriaal verhaalsbeslag leggen indien hij beschikt over een executoriale titel. Indien een schuldeiser conservatoir beslag heeft gelegd en vervolgens een executoriale titel heeft verkregen die voor tenuitvoerlegging vatbaar is, gaat het conservatoir beslag volgens artikel 704 lid $1 \mathrm{Rv}$ over in een executoriaal beslag, mits de verkregen titel aan de beslagene, en zo het beslag onder een derde is gelegd ook aan deze, is betekend. Onder een executoriale titel is mede begrepen een grosse van een in Nederland verleden notariële akte. Bij een conservatoir beslag kan onder meer gedacht worden aan een conservatoir beslag ter verzekering van nietopeisbare vorderingen uit hoofde van de wettelijke verdeling. ${ }^{26}$

\section{Korte samenvatting}

In dit artikel heb ik aandacht besteed aan een aantal gevallen waarin het in het erfrecht van belang is dat tenuitvoerlegging kan plaatsvinden van een grosse van een (uittreksel van een) notariële akte. In sommige gevallen, zoals bij de geldvorderingen uit hoofde van de wettelijke verdeling, kan de mogelijkheid die artikel $430 \mathrm{Rv}$ biedt een (extra) reden zijn om de vaststelling van de geldvorderingen bij notariële akte te doen plaatsvinden. In het geval van een geldlegaat, dat in het algemeen bij openbare uiterste wil wordt gemaakt, is het van belang dat de legataris met de grosse van een uittreksel van de uiterste wil tot verhaalsexecutie kan overgaan. Betaling zal veelal spoedig plaatsvinden nadat de legataris de erfgenamen of de executeur die traineren met de afgifte van het legaat heeft aangekondigd tot tenuitvoerlegging van de grosse te zullen overgaan.

26. Zie daarover S. Perrick, Het belang van conservatoir beslag ter verzekering van niet-opeisbare erfrechtelijke vorderingen, Tijdschrift Erfrecht 2016, afl. 5, p. 88-93. Daar merk ik in par. 7 op geen wettelijke belemmering te zien dat de voorzieningenrechter op de voet van art. 700 lid 3 Rv bepaalt dat het instellen van de eis in de hoofdzaak geschiedt binnen een bepaald tijdvak na het overlijden van de langstlevende. $\mathrm{Na}$ het overlijden van de langstlevende bestaat geen behoefte meer aan het instellen van een eis in hoofdzaak omdat het conservatoir beslag dan in een executoriaal beslag kan overgaan door betekening van de grosse van de notariële akte. 